in all activities of daily living. The case illustrates the need to be aware of adverse effects of all drugs-even those considered to be among the safest.

\section{Discussion}

Nitrous oxide can interfere with the metabolism of vitamin B-12 and can cause spinal cord degeneration. ${ }^{12}$ The mechanism of neuropathology with nitrous oxide is due to inactivation of vitamin B-12, which leads to impaired methionine synthesis. The cobalt atom in vitamin B-12 donates two electrons to nitrous oxide $^{1}$ :

$$
\mathrm{Co}^{+}+\mathrm{N}_{2} \mathrm{O} \rightarrow \mathrm{Co}^{3+}+\mathrm{N}_{2}+\mathrm{O}^{2-}
$$

This is followed by the rapid reaction of $\mathrm{Co}^{3+}$ with $\mathrm{Co}^{+}$ resulting in the failure of methylation of basic proteins in myelin sheaths ${ }^{3}$ :

$$
\mathrm{Co}^{3+}+\mathrm{Co}^{+} \rightarrow 2 \mathrm{Co}^{2+}
$$

Polyneuropathy and spinal cord degeneration are the most common neurological manifestations of vitamin B-12 deficiency. The diagnosis is made clinically and by finding a decreased serum vitamin B-12 concentration. (Often there is no macrocytosis on the blood film, as in this case). The typical magnetic resonance imaging findings show a typical dorsal cervical cord lesion. ${ }^{4}$

Reports describing spinal cord degeneration of the cord after treatment with nitrous oxide have generally been attributed it to prolonged exposure to the gas and poor nutrition. ${ }^{56}$ Toxicity related to the prolonged intermittent exposure of low concentrations of nitrous oxide has been described in experimental animals. ${ }^{78}$

In this case, nitrous oxide probably complicated longstanding malnutrition, causing neurological com- plications with intermittent administration of small amounts of nitrous oxide. The good safety record and rapid action of 50:50 nitrous oxide-oxygen mixtures in pain management make it a desirable agent, particularly for pain during medical procedures. It is important, however, that health workers who prescribe nitrous oxide are aware of its potential long term adverse effects, particularly in patients with chronic illness. After this incident, our hospital has put in place appropriate procedures to guard against a repetition.

Contributors: All authors were actively involved with the case and participating in writing the paper. $\mathrm{MD}$ is the guarantor Funding: None.

Competing interests: None declared.

Ethical approval: Not needed.

1 Filippo TS, Holder WD. Neurologic degeneration associated with nitrous oxide anaesthesia in patients with vitamin B12 deficiency. Arch Surg 1993;128:1391-5.

2 Schilling RF. Is nitrous oxide a dangerous anaesthetic for vitamin B12 deficient subjects? JAMA 1986;255:1605-6.

3 Small DH, Carnegie PR, Anderson R McD. Inhibition of protein methylation in myelin mimics lesions due to vitamin B12 deficiency. Proc Aust Biochem Soc 1980;13:113.

4 Ilniczky S, Jelencsik I, Kenez J, Szirmai I. MR findings in subacute combined degeneration of the spinal cord caused by nitrous oxide anaesthesia-two cases. Eur J Neurol 2002;9:101-4.

5 Iwata K, O'Keefe GB, Karanas A. Neurologic problems associated with nitrous oxide abuse in a non-healthcare worker. Am J Med Sci 2001;322:173-4.

6 Louis-Ferdinand RT. Myelotoxic, neurotoxic and reproductive adverse effects of nitrous oxide. Adverse Drug React Toxicol Rev 1994;13:193-206.

7 Koblin DD, Everman BW. Vitamin B12 and folate status in rats after chronic administration of ethanol and acute exposure to nitrous oxide. chronic administration of ethanol and
Alcohol Clin Exp Res 1991;15:543-8.

8 Abdul-Kareen HS, Sharma RP, Drown DB. Effects of repeated intermittent exposures to nitrous oxide on central neurotransmitters and hepatic methionine synthetase activity in CD-1 mice. Toxicol Ind Health 1991;7:97-108.

(Accepted 12 March 2004)

\title{
$Q \mathcal{E} A$
}

\section{Cocaine and amphetamine combined}

\section{Question}

What would happen if someone was to take a mixture of cocaine and amphetamine at the same time?

Elizabeth M Sobic, medical student, Birmingham

\section{Answer}

It depends on dose, route of administration, and history of drug misuse.

Both cocaine and the amphetamines developed originally for clinical use (including methamphetamine (or "ice")) are psychomotor stimulants. ${ }^{1}$ They have broadly similar actions at the synaptic level (such as blocking reuptake of dopamine released from the meso-limbo-cortical dopamine terminals), the level of mood and alertness, and the behavioural level. Some other amphetamines (such as phenylamphetamine (mescaline)) have slightly different actions, based, like ecstasy (MDA, MDMA), on a predominantly seratonergic effect.

All can be taken by different routes, including oral, intranasal, intravenous, or smoked (the freebase of cocaine "crack" or methamphetamine "crystal"). In a drug-naive, low dose, intranasal or oral user the stimulant effect would probably be additive at the time of use, with the longer half life of amphetamines giving a much prolonged "high" compared with cocaine by itself. Tolerance in regular users builds up to a great degree, so naive users are at immediate risk of overdose (such as with severe cardiovascular effects) if they take the dose of their more experienced friends, say at a party or club. Fatal overdoses are particularly common if taken in combination with other substances, especially injected heroin (a "snowball" or "speedball") and abundant alcohol (cocaethylene is produced). A prolonged run of stimulant use, say continuously over a weekend, always produces an unpleasant emotional state very different from the initial euphoria-people who try desperately to prolong the "high" may end up feeling desperate and behave in a pretty wild or frightened way.

In my unpublished work on London stimulant users, dependent drug users significantly preferred cocaine to amphetamine (although it is more expensive)-the first stimulant drug used was predominantly amphetamine in early adolescence. One of the peculiar phenomena of these drugs is priming (early low dose exposure to either one increases the effect of later use of the other), a type of learning. Heavy users of intravenous stimulants show their proconvulsant action-over repeated use, seizures are kindled. This is one (of many) reasons why I would not recommend substitution of prescribed methamphetamine or methylphenidate for former illicit cocaine users.

Woody Caan, professor of public health, APU, Chelmsford

1 Caan W, de Belleroche J. Drink, drugs and dependence. From science to clinical practice. London: Routledge, 2002.

http://bmj.com/cgi/qa-display/short/bmj_el;50470

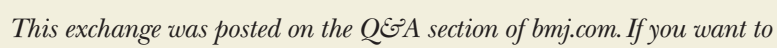
respond to the question, or ask a new question of your own, follow the link above or go to http://bmj.com/q\&a 